Mini Review

\title{
Cellulose-based membrane for adsorption of dye in batik industry wastewater
}

Keywords: fabrics, hydroxyl group, covalent bond, batik cloth, azo, diazo, or metal complex, anthraquinone dye, pollution

Abbreviations: PVA, polyvinyl alcohol; PEG, polyethylene glycol; CMC, carboxymethyl cellulose; MB, methylene blue

\section{Introduction}

Batik is a traditional Indonesian cloth with a very diverse pattern of fabrics depending on the cultural background of the area where batik originates. Whatever the pattern of the batik cloth, all use almost the same dyeing technique, namely using synthetic and waxresist dyes. The batik coloring process produces residual dye from the washing and rinsing process of the batik cloth. ${ }^{1}$ Dyes commonly used in the batik industry are synthetic dyes because they are easy to obtain, cheap and produce bright colors and also because they are reactive due to reactive functional group and easily binds to the hydroxyl group of the fabric to form a covalent bond. ${ }^{2}$ Types of batik dyes include anthraquinone-based, acidic, alkaline, containing azo, diazo, or metal complex. ${ }^{3}$ In addition, synthetic batik dyes also contain heavy metals, namely $\mathrm{Cd}, \mathrm{Cr}, \mathrm{Pb}, \mathrm{Co}, \mathrm{Cu}, \mathrm{Hg}, \mathrm{Ni}, \mathrm{Mg}, \mathrm{Fe}$ and $\mathrm{Mn} .{ }^{4}$ One of the blue synthetic dyes that is often used in the coloring of the batik cloth is Reactive Blue 19, also known as Blue KN-R, it is a type of anthraquinone dye and is more difficult to decolorize than azo dyes because of its conjugated structure. ${ }^{5}$ Indigosol dyes need to be activated using a solution of acid or nitrate and cause chromium residue in the waste water. ${ }^{6}$ Unfortunately, most of the batik industry still discharges the waste from the batik dyeing process, directly into river bodies. This can cause pollution, because it causes changes in the quality, color and smell of river water. Efforts to overcome river water pollution can be carried out biologically, chemically and physically.

Filtering is a commonly applied physical method. Based on the size of the filtered particles, the types of filtering used are divided into four, namely microfiltation $(100 \mathrm{~nm}-10 \mu \mathrm{m})$, ultrafiltration (2$100 \mathrm{~nm})$, nanofiltration $(1-2 \mathrm{~nm})$ and reverse osmosis-RO $(0.1-1 \mathrm{~nm}){ }^{7}$ Among the four types of membranes, the nanofiltration membrane is the most efficient, because its structure can filter wastewater into usable water. ${ }^{8}$ The waste water for the batik industry in Malaysia contains a lot of Remazol and Vinyl Sulphone dyes. Filtering using a nanofiltration membrane made of aromatic polyamide with nonwoven and fibreglass wounded fibres support can filter water with Remazol Turquiose Blue dye more effectively than water with Remazol Yellow and Remazol Red dyes, which are characterized by the lowest color intensity after the filtering process. ${ }^{9}$ The use of fiberglass in membrane technology requires quite high production costs, encouraging the search for alternative materials with more economical production costs, for example the use of cellulose. One of the materials used in the process of filtering wastewater is a cellulose-based membrane. This paper is a mini review of cellulose-based membranes for filtering waste water from the batik industry, especially waste caused by synthetic dyes.

\section{Cellulose acetate-based membrane}

Putri et al. ${ }^{6}$ made membranes from cellulose water hyacinth, polyvinyl alcohol (PVA) and polyethylene glycol (PEG) with a
Volume 4 Issue 6 - 2020

\section{Firda Aulya Syamani}

Research Center for Biomaterials, Indonesian Institute of Sciences, Indonesia

Correspondence: Firda Aulya Syamani, Research Center for Biomaterials, Indonesian Institute of Sciences, Jalan Raya Bogor Km. 46, Cibinong, Jawa Barat, Indonesia, Email firda.syamani@biomaterial.lipi.go.id

Received: December 03, 2020 | Published: December 14, 2020

ratio of cellulose: PVA: $\mathrm{PEG}=6.5: 2.5: 1(\mathrm{w} / \mathrm{w})$, which can adsorb $38.75 \%$ chromium. ${ }^{6}$ However, the filtering ability of cellulose-based membranes is still low, due to the compact and inactive structure of cellulose. An effort to improve this is by modifying cellulose into cellulose acetate, which is then used as a material for making membranes. Replacement of the hydrogen atom in the hydroxyl group of cellulose with an acetyl group $\left(\mathrm{CH}_{3}=\mathrm{CO}\right)$, occurs through the esterification reaction of cellulose with acetic acid and acetic anhydride using a sulfuric acid catalyst (Figure 1). The esterification reaction which replaces 2 hydroxyl groups in cellulose produces cellulose triacetate which has properties, high melting temperature $\left(300{ }^{\circ} \mathrm{C}\right)$, high crystallinity and can only be dissolved in certain organic solvents, such as methylene chloride.

Cellulose acetate-based membranes can be used for both ultrafiltration, nanofiltration and RO filtering techniques. The use of cellulose acetate as a membrane ultrafiltration has been carried out since 1975. Cellulose acetate is dissolved in acetone and magnesium perchlorate is added, then it is used to separate various compounds, ranging from low molecular weight (58), namely $\mathrm{NaCl}$, to high molecular weight compounds $(160,000)$ namely $\gamma$-globulin. The filtering results show that at $65{ }^{\circ} \mathrm{C}, 100 \%$ of the globulin can be filtered and only $6 \% \mathrm{NaCl}$ can be filtered. When the filtering process temperature was increased to $85^{\circ} \mathrm{C}$, the ability to filter $\mathrm{NaCl}$ increased to $23 \% .^{10}$ The reverse osmosis membrane made of cellulose acetate was able to filter $86.5 \%$ of Turquiose Blue and $87 \%$ of Yellow dyes, after 4 stages of filtering. ${ }^{3}$ The weakness of cellulose acetate-based membranes is the absence of reactive functional groups, resulting in 
low separation efficiency based on the affinity principle. ${ }^{11}$ In addition, cellulose acetate-based membranes have low permeability and tend to be prone to fouling. Thus, various modifications are made, for example by surface modification or mixing.

Cellulose acetate-based membrane modification (produced by electrospinning technique) by deacetylation process (with $0.5 \mathrm{~mol} . \mathrm{L}^{-1}$ $\mathrm{NaOH}$ solution), followed by a coating process with polydopamine. The membrane composite manufacturing stage, begins with dissolving acetic acid powder in a solvent mixture of acetone and $\mathrm{N}, \mathrm{N}$-Dimethylacetamide $(2: 1)$, oscillated for 24 hours at $333 \mathrm{~K}$ to produce an electrospinning solution containing $17 \%$ cellulose acetate. The nanofiber membrane of cellulose acetate was then deacetylated using 0.5 mol. $\mathrm{L}^{-1} \mathrm{NaOH}$ solution. Furthermore, it was coated with polymerized dopamine after stirring at $30{ }^{\circ} \mathrm{C}$ for 40 hours. The resulting membrane was able to increase the adsorption capacity of methylene blue dye to $88.2 \mathrm{mg} \cdot \mathrm{g}^{-1}$ at a temperature of $25^{\circ} \mathrm{C}$ and a $\mathrm{pH}$ of 6.5 after adsorption for $30 \mathrm{~h} .{ }^{13}$ The mixing of chitosan and cellulose acetate is intended to improve the hydrophilic properties of the membrane in the presence of reactive groups (amino and hydroxyl groups) of chitosan. ${ }^{14}$ The challenge that must then be resolved is how to increase the resistance (durability) of chitosan-cellulose acetate membrane composites and avoid segregation that can arise due to the difference in surface pressure between chitosan and cellulose acetate. Gopi et al. ${ }^{15}$ made a composite membrane from cellulose acetate and chitosan with a ratio of $14: 1 ; 12: 2 ; 8: 3$ with glacial acetic acid solvent, then sonified for 45 minutes and dried at room temperature for 24 hours. ${ }^{15}$ Modifications to the deacetylation process were carried out by immersing the composite membrane sheets in $6 \mathrm{M} \mathrm{KOH}$ for 3 hours, followed by rinsing using distilled water 2 times, then drying at room temperature. The deacetylation process effectively removes acetate groups, resulting in a positive charge on the membrane surface so that it efficiently adsorbs anionic dyes in wastewater.

\section{Carboxymethyl cellulose-based membrane}

Modification of cellulose by carbon methylization will produce carboxymethyl cellulose (CMC), as illustrated in Figure 2. CMC is a long chain anionic polysaccharide, which is soluble in water. The use of CMC as a membrane to adsorb dyes in the batik industry wastewater has been carried out by many researchers. The adsorption of dye waste with CMC membranes was carried out using methylene blue (MB). ${ }^{17,18}$ The adsorption capacity of methylene blue by CMC reached $300 \mathrm{mg} . \mathrm{g}^{-1}$, higher than membranes made of pure cellulose (50 mg. $\left.\mathrm{g}^{-1}\right) .{ }^{17}$ Uptake of MB by the CMC membrane is rapid and reaches equilibrium after 30 minutes. $\mathrm{CMC}$ with a degree of substitution of 0.09 showed the adsorption capacity of MB (concentration 663 mg. $\mathrm{L}^{-1}$ ) of $652 \mathrm{mg} \cdot \mathrm{m}^{-1}$, while the uptake capacity of MB by CMC with DS 0.06 , was $369 \mathrm{mg} \cdot \mathrm{g}^{-1}$, at $\mathrm{pH} 8$ and temperature $30{ }^{\circ} \mathrm{C} .{ }^{18}$ The weakness of the $\mathrm{CMC}$ membrane is that its mechanical strength is still low, thus limiting its service life. The development of CMC-based composite membranes is carried out to increase mechanical strength, accelerate and increase the adsorption capacity of dyes. Other than in form of membrane, CMC was utilized to adsorb dye, in form of beads, microspheres, hydrogel or block of gel. Liu et al. (2017) made a CMC-k-carragenan-activated montmorillonite composite bead. MB removal (\%) exceeded $92 \%$ after 120 min using CMC / $\mathrm{kC} / \mathrm{AMMT}$ (1: $1: 0.4$ ratio). ${ }^{19}$ The reusability of composite beads was good for five adsorption-desorption cycles. ${ }^{19}$ The microspheres of CMC crosslinked with epichlorohydrin were successfully adsorb 998.2 $\mathrm{mg} . \mathrm{m}^{-1} \mathrm{MB}$ and could be regenerated and reused with acidic buffer solution at $\mathrm{pH} 4.003$ at least 10 times. $^{20}$

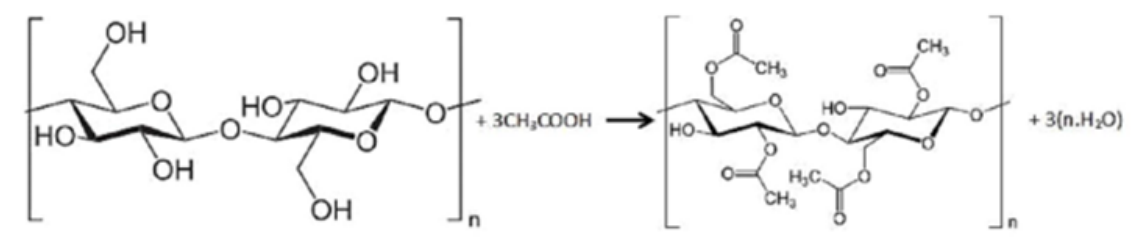

Figure I The reaction of cellulose with acetic acid produces cellulose acetate.

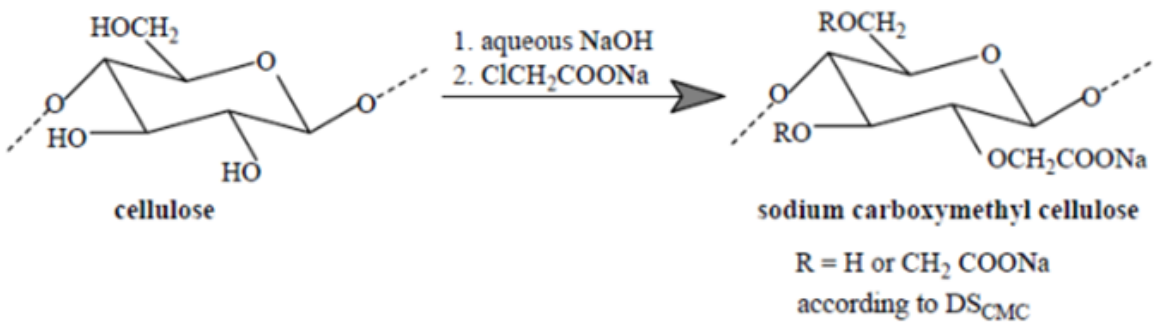

Figure 2 Reaction scheme of the carboxymethylation of cellulose. ${ }^{16}$

The hydrogels of CMC-acrylamide-graphene oxide were utilized for adsorption of Acid Blue-133 with maximum adsorption capacity of $185.45 \mathrm{mg} . \mathrm{g}^{-1} \cdot{ }^{21} \mathrm{CMC}$ and tannin were combined and crosslinked with epichlorohydrin, shows maximum adsorption capacity of 1300 $\mathrm{mg} . \mathrm{g}^{-1}$, when concentration of MB was lower than $2000 \mathrm{mg} \cdot \mathrm{L}^{-1} .^{22}$ Zhang et al. (2014) developed a CMC composite membrane by grafting acrylic acid (CA) and was able to adsorb Methyl Orange, Disperse Blue 2BLN and malachite green chloride reached to $84.2 \%$ (at $\mathrm{pH}<4,50^{\circ} \mathrm{C}$ ), $79.6 \%$ (at $\mathrm{pH} 7,50^{\circ} \mathrm{C}$ ) and $99.9 \%$ (at $\mathrm{pH}>9,50^{\circ} \mathrm{C}$ ), respectively. The surface area of CMC-CA adsorbent was 594.45 $\mathrm{m} 2 / \mathrm{g}$, with micropore volume and average pore diameter of 0.093 $\mathrm{cm} 3 / \mathrm{g}$ and $6.5 \mathrm{~nm}$, respectively. ${ }^{23}$ Gorgieva et al (2020) developed a composite membrane from $\mathrm{CMC}$ as an adsorbent for anionic dyes and cellulose nanofibers as a reinforcing filler with citric acid as a cross linking agent. To obtain a highly porous $(>90 \%)$ membrane structure with a pore size between a few $\mathrm{nm}$ to $200 \mu \mathrm{m}$, the freeze-cast technique 
is used. The resulting membranes showed high and stable flux rates $\left(150-190 \mathrm{~kL} / \mathrm{m}^{2} \mathrm{~h} \mathrm{MPa}\right)$ with $\sim 100 \%$ cationic dye adsorption, fast dynamic $(8,536-5,446 \mathrm{~kg} / \mathrm{g} \mathrm{min})$ and capacity $(1828-1398 \mathrm{~g} / \mathrm{kg})$, high dye removal capacity $(\geq 90 \%)$ even after 50 th reusing cycle. ${ }^{24}$ In addition to the presence of reactive functional groups, the adsorbent structure also greatly affects the effectiveness of filtering dye particles in batik industrial wastewater. Nano-adsorbent composite of CMC / graphitic-carbon nitride / zinc-oxide prepared by sol-gel technique, showed the adsorption ability of methylene violet of $96.43 \mathrm{mg} / \mathrm{g}$ at $\mathrm{pH} 8$, because it has a large surface area, namely $9,214 \mathrm{~m}^{2} / \mathrm{g} .{ }^{25}$

\section{Concluding remarks}

Dyes from the batik industry can contaminate river waters if not treated first. A simple method that is effective in reducing river water pollution due to dye waste is filtering using a membrane. Membranes made from cellulose, especially those that have been modified into cellulose acetate or carboxy methyl cellulose, are able to function to filter out particulate dyes. Even the performance increases when combined with acrylamide-graphene oxide or graphitic carbon nitride - zinc oxide.

\section{Acknowledgments}

None.

\section{Conflits of interest}

The authors declare that there is no conflict of interest.

\section{Funding}

None.

\section{References}

1. Felaza E, Priadi CR. Implementation of Cleaner Production in a Natural Dye Batik Industry SME: A way to Enhance Biodegradability of Batik Wastewater?. MATEC Web of Conferences. 2016;62:05003.

2. Karamah EF, Nurcahyani PA. Degradation of Blue KN-R Dye in Batik Effluent by an Advanced Oxidation Process Using a Combination of Ozonation and Hydrodynamic Cavitation. Indones. J. Chem., 2019;19(1):41-47.

3. Sathiyamoorthy M, Gashaw M, Tesfaye M, et al. The removal of colour from synthetic textile dye effluent using cellulose acetate reverse osmosis membrane. Int J Adv Res Inf Technol Eng. 2012;1(4):25-42.

4. Budiyanto S, Anies, Purnaweni H, et al. Environmental Analysis of The Impacts of Batik Waste Water Polution on The Quality of Dug Well Water in The Batik Industrial Center of Jenggot Pekalongan City. E3S Web of Conferences. 2018;31:09008.

5. Dong XL, Zhou JT, Liu Y. Peptone-induced biodecolorization of reactive brilliant blue (KN-R) by Rhodocyclys gelatinosus XL-1. Process Biochem. 2003;39(1):89-94.

6. Putri CA, Yulianti I, Desianna I, et al. Water hyacinth cellulose-based membrane for adsorption of liquid waste dyes and chromium. IOP Conf. Series: Journal of Physics Conf Series. 2018;1008:012014.

7. Yang Z, Zhou Y, Feng Z, et al. A Review on Reverse Osmosis and Nanofiltration Membranes for Water Purification. Polymers. 2019;11:1252.
8. Chen X, Shen Z, Zhu X, et al. Advanced treament of textile wastewater for use using electrochemical oxidation and membrane filtration. Water SA. 2005;31:127-132.

9. Rashidi HR, Nik Sulaiman NM, Hashim NA. Batik industry synthetic wastewater treatment using nanofiltration membrane. Procedia Eng. 2012;44:2010-2012

10. Kutowy O, Sourirajan S. Cellulose Acetate Ultrafiltration Membranes. $J$ App Polym Sci. 1975;19:1449-1460.

11. Klein E. Affininty membranes:a 10-years review. J Membr Sci. 2000;179:1-27.

12. Shen SS, Chen H, Wang RH, et al. Preparation of antifouling cellulose acetate membranes with good hydrophilic and oleophobic surface properties. Mater Lett. 2019;252:1-4

13. Cheng J, Zhan C, Wu J, et al. Highly Efficient Removal of Methylene Blue Dye from an Aqueous Solution Using Cellulose Acetate Nanofibrous Membranes Modified by Polydopamine. ACS Omega. 2020; 5: 5389-5400

14. Ghaee A, Shariaty-Niassar M, Barzin J, et al. Preparation of chitosan/ cellulose acetate composite nanofiltration membrane for wastewater treatment. Desalin. Water Treat. 2015;57(31):14453-14460.

15. Gopi S, Pius A, Kargl R, et al. Fabrication of cellulose acetate/chitosan blend films as efficient adsorbent for anionic water pollutants. Polym. Bull. 2019;76:1557-1571.

16. Heinze T, Pfeiffer K. Studies on the synthesis and characterization of carboxymethyl cellulose. Die Angewandte Makromolekulare Chemie. 1999;266:37-45.

17. Yan H, Zhang W, Kan X, et al. Sorption of methylene blue by carboxymethyl cellulose and reuse process in a secondary sorption. Colloids and Surfaces A. 2011;380:143-151

18. Begum HA, Mahbub MK. Effectiveness of Carboxymethyl Cellulose for the Removal of Methylene Blue from Aqueous Solution. Dhaka Univ J Sci. 2013;61(2):193-198.

19. Liu C, Omer AM, Ouyang XK. Adsorptive removal of cationic methylene blue dye using carboxymethyl cellulose/k-carrageenan/ activated montmorillonite composite beads: Isotherm and kinetic studies. Int J Biol Macromol. 2018;106:823-833.

20. Lin Q, Gao M, Chang J, et al. Highly effective adsorption performance of carboxymethyl cellulose microspheres crosslinked with epichlorohydrin. J Appl Polym Sci. 2017;134(2):1-3.

21. Varaprasad K, Jayaramudu T, Sadiku ER. Removal of dye by carboxymethyl cellulose, acrylamide and graphene oxide via a free radical polymerization process. Carbohydr. Polym. 2017;164:186-194.

22. Ting Z, Peng Z. Bio-adsorbent from carboxymethyl cellulose and tannin for dye adsorption. J Macromol Sci B. 2016;57(3):177-183.

23. Zhang G, Yi L, Deng $\mathrm{H}$, et al. Dyes adsorption using a synthetic carboxymethyl cellulose-acrylic acid adsorbent. $J$ Environ Sci. 2014;26:1203-1211.

24. Gorgieva S, Vogrinčič R, Kokol V. The Effect of Membrane Structure Prepared from Carboxymethyl Cellulose and Cellulose Nanofibrils for Cationic Dye Removal. J Polym Environ. 2019;27:318-332.

25. Sharma G, Kumar A, Sharma S, et al. Carboxymethyl cellulose structured nano-adsorbent for removal of methyl violet from aqueous solution: isotherm and kinetic analyses. Cellulose. 2020; 7:3677-3691. 